\title{
Supercritical fluid-mediated liposomes containing cyclosporin A for the treatment of dry eye syndrome in a rabbit model: comparative study with the conventional cyclosporin A emulsion
}

\author{
This article was published in the following Dove Press journal: \\ International Journal of Nanomedicine \\ 8 August 2014 \\ Number of times this article has been viewed
}

\section{Pankaj Ranjan Karn' \\ Hyun Do Kim ${ }^{1,2}$ \\ Han Kang ${ }^{1,2}$ \\ Bo Kyung Sun ${ }^{1,2}$ \\ Su-Eon Jin ${ }^{2}$ \\ Sung-Joo Hwang ${ }^{1,2}$}

'Yonsei Institute of Pharmaceutical Sciences, ${ }^{2}$ College of Pharmacy, Yonsei University, Yeonsu-gu, Incheon, Republic of Korea
Correspondence: Sung-Joo Hwang College of Pharmacy, Yonsei University, 85 Songdogwahak-ro, Yeonsu-gu, Incheon 406-840, Republic of Korea

$\mathrm{Tel}+82327494518$

Fax +82327494105

Email sjhII@yonsei.ac.kr
Background: The objective of this study was to compare the efficacy of cyclosporin (CsA)-encapsulated liposomes with the commercially available CsA emulsion (Restasis ${ }^{\circledR}$ ) for the treatment of dry eye syndrome in rabbits.

Methods: Liposomes containing CsA were prepared by the supercritical fluid (SCF) method consisted of phosphatidylcholine from soybean (SCF-S100) and egg lecithins (SCF-EPCS). An in vitro permeation study was carried out using artificial cellulose membrane in Franz diffusion cells. Dry eye syndrome was induced in male albino rabbits and further subdivided into untreated, Restasis ${ }^{\circledR}$-treated, EPCS, and S100-treated groups. Tear formation in the dry-eyeinduced rabbits was evaluated using the Schirmer tear test. All formulations were also evaluated by ocular irritation tests using the Draize eye and winking methods with the determination of CsA concentration in rabbit tears.

Results: After the treatment, the Schirmer tear test value significantly improved in EPCS-treated $(P=0.005)$ and $\mathrm{S} 100$-treated $(P=0.018)$ groups compared to the Restasis ${ }^{\circledR}$-treated group. The $\mathrm{AUC}_{0-24 \mathrm{~h}}$ for rabbit's tear film after the administration of SCF-S100 was $32.75 \pm 9.21 \mu \mathrm{g} \cdot \mathrm{h} / \mathrm{mg}$ which was significantly higher than that of $24.59 \pm 8.69 \mu \mathrm{g} \cdot \mathrm{h} / \mathrm{mg}$ reported with Restasis ${ }^{\circledR}$. Liposomal CsA formulations used in this study showed lower irritation in rabbit eyes compared with Restasis ${ }^{\circledR}$.

Conclusion: These results demonstrate that the novel SCF-mediated liposomal CsA promises a significant improvement in overcoming the challenges associated with the treatment of dry eyes.

Keywords: cyclosporin A, liposomes, supercritical fluid, dry eye syndrome

\section{Introduction}

Dry eye syndrome (DES) is a common ophthalmic condition, which is defined as a disorder of the tear film due to tear deficiency or excessive evaporation. ${ }^{1}$ DES causes damage to the interpalpebral ocular surface that is associated with symptoms of discomfort. ${ }^{2}$ It is believed to affect millions of people worldwide. ${ }^{3}$ The use of topical steroids has been shown to produce relief from dry eye symptoms, but longterm use results in potential side effects such as glaucoma and cataract. ${ }^{4}$ Therefore, the development of agents is essential for chronic use of the drug without serious adverse effects.

Cyclosporin A (CsA), a neutral and hydrophobic cyclic peptide of eleven amino acids, ${ }^{5}$ is isolated from a fungus Tolypocladium inflatum Gams. ${ }^{6}$ The mechanism of action of how CsA increases tear production is still unknown, but it seems to be related 
to its immunomodulatory activity, which decreases local inflammation. ${ }^{7}$ In the cytoplasm, CsA binds to its immunophilin, cyclophilin, forming a complex and the complex then binds and blocks the function of the enzyme calcineurin that results in the suppression of the expression of cytokine genes and thereby inhibits T-cell activation. ${ }^{6,8,9} \mathrm{CsA}$ has been shown to be an effective therapeutic agent for treatment of dry eye symptoms, ${ }^{8,10}$ leading to approval of an oil-in-water $0.05 \%$ CsA emulsion (Restasis ${ }^{\circledR}$; Allergan Inc., Irvine, CA, USA) in December 2002. ${ }^{6}$ Restasis $^{\circledR}$ formulation contains castor oil, of which the most common side effect is ocular burning or irritation following the long-term use of Restasis ${ }^{\circledR} .{ }^{11}$ In addition, adverse reactions such as itching, redness, visual disturbance, and eye pain have limited its use. ${ }^{12}$ Poor ocular tolerance, low bioavailability, and instability are also the major drawbacks reported with Restasis ${ }^{\circledR} .5,13$

Over the past few decades, a number of studies have focused on the potential application of liposomes as alternatives to the conventional therapy of CsA. ${ }^{5,13-16}$ In addition, liposomal technology has also been studied for the ocular delivery of CsA, ${ }^{17-19}$ but the large-scale manufacture of these liposomes is expensive and challenging. Liposomes were reported to enhance the permeation of poorly adsorbed drug by binding to the corneal surface and improving residence time. ${ }^{20}$ These liposomes could be used to improve the pharmacokinetic profile, enhance therapeutic effect, and reduce toxicity associated with higher doses. ${ }^{21}$ Despite these advantages, no studies have been published regarding the use of liposomal CsA in the treatment of DES.

Large-scale production and stability issues of liposomes are major hurdles to overcome in using liposomes as candidates for CsA delivery. ${ }^{22,23}$ In our previous study, ${ }^{5}$ we reported the novel formulations of liposomal CsA using the supercritical fluid of carbon dioxide ( $\mathrm{SCF}-\mathrm{CO}_{2}$ ) method that could address the issues of scaled-up production and stability of liposomes. In the present study, we prepared liposomal formulations of CsA using phosphatidylcholine from soybean (SCF-S100) and egg lecithins (SCF-EPCS) based on the SCF-CO ${ }_{2}$ method. Both of these liposomes were easy to manufacture and require low-cost of production. The aim of this study was to investigate the effectiveness of SCF-mediated liposomal CsA for the treatment of DES in rabbits compared with conventional CsA emulsion, Restasis ${ }^{\circledR}$. The efficiency of SCF-mediated CsA liposomes in producing tears was tested in DES-induced rabbit eyes by analyzing the changes in the Schirmer tear test (STT). The ocular irritation tests and concentration determination of CsA in tear films were also carried out to investigate the strength of newly proposed liposomal formulations.

\section{Materials and methods Materials}

Restasis $^{\circledR}$ emulsion (Allergan Inc.) was purchased from a local market. CsA was supplied from Concord Drugs Limited (Hyderabad, India). Ethyl alcohol (purity 99.9\%) and methyl alcohol (purity 99.5\%) were purchased from Samchun Pure Chemical Co. Ltd., (Gyeonggi-do, Republic of Korea). A dialysis membrane (molecular weight cut-off: 14,000 Dalton (Da)) from Sigma-Aldrich Co. (St Louis, MO, USA) was used. Purified water of Milli-Q quality (Milli-Q Reference; EMD Millipore, Billerica, MA, USA) was used throughout the study.

\section{Preparation of CsA-containing liposomes}

Liposomes were prepared using the SCF- $\mathrm{CO}_{2}$ method described in our previous reports. ${ }^{5,24}$ Two different formulations of CsA SCF-S100 and SCF-EPCS liposomes containing naturally derived phosphatidylcholine from soybean (Lipoid S100; Lipoid GmbH, Ludwigshafen, Germany $)^{5}$ and egg lecithin (Lipoid EPCS; Lipoid GmbH) ${ }^{24}$ were used in this study. In brief, $200 \mathrm{mg}$ of phospholipid, $100 \mathrm{mg}$ of cholesterol, and $50 \mathrm{mg}$ of CsA were dissolved in ethanol and the mixture was then sealed in a reaction vessel with $900 \mathrm{mg}$ of anhydrous lactose powder. The supercritical $\mathrm{CO}_{2}$ was pumped to the vessel at an optimized temperature of $45^{\circ} \mathrm{C}$ and pressure of $10 \mathrm{MPa}$. A thin film of CsA-phospholipid mixture coated on the surface of lactose was formed upon depressurization of the vessel. The resulting thin film was then hydrated at $50^{\circ} \mathrm{C}$ to form multilamellar liposomes. Prepared liposomes were homogenized by passing through an ultra-high-pressure homogenizer (Nano DeBEE; BEE International, South Easton, MA, USA) to obtain the nanosized liposomes. An operating pressure of 30,000 psi and nine numbers of run were selected based on the previous optimization study. ${ }^{24}$

\section{Particle size and polydispersity index (PDI) determination}

Both SCF-S100 and SCF-EPCS liposomes were properly diluted with filtered Milli-Q water $(0.45 \mu \mathrm{m}$ pore size polytetrafluoroethylene Whatman ${ }^{\mathrm{TM}}$ filters; GE Healthcare Life Sciences, Pittsburgh, PA, USA) before measurements to adjust the intensity. The particle size and PDI of liposomes and Restasis ${ }^{\circledR}$ were measured using a particle size analyzer (ELS-Z; Otsuka Electronics Co., Ltd., Osaka, Japan) at room temperature. The PDI was determined as a measure of the level of homogeneity of particle sizes and a PDI $<0.1$ represented monodispersion, while PDI $>0.1$ represented polydispersion of liposomal vesicles. ${ }^{5}$ 


\section{Scanning electron microscopy (SEM) of liposomes}

SCF-S100 liposomes were freeze-dried using a laboratory freeze-dryer (FD 5512; Ilshin Lab Co. Ltd., Gyeonggi-do, Republic of Korea) in order to perform SEM. The morphology of anhydrous lactose powder and CsA entrapped SCFS100 liposomes was investigated by Field Emission-SEM (JSM-7100F, JEOL, Tokyo, Japan) at an accelerating voltage of $5.0 \mathrm{kV}$. The samples were prepared on aluminum stubs and coated with gold under argon atmosphere by means of a sputter coater.

\section{High-performance liquid chromatography (HPLC) analysis of CsA}

CsA was analyzed by the HPLC method explained in Karn et al. ${ }^{5}$ In brief, homogenized liposomes were appropriately diluted and dispersed with ultra-pure water filtered with a $0.45 \mu \mathrm{m}$ polytetrafluoroethylene syringe filter and centrifuged to separate free drug. After centrifugation, the supernatants were discarded and the pellets were dissolved with ultra-pure filtered water to make $0.05 \%$ CsA. Samples were directly assayed by HPLC (Agilent 1200 Series System; Agilent Technologies, Santa Clara, CA, USA) using a $\mathrm{C}_{18}$ analytical column $(4.6 \mathrm{~mm} \times 150 \mathrm{~mm}, 3 \mu \mathrm{m}$; SUPELCO Analytical, Bellafonte, CA, USA) at $70^{\circ} \mathrm{C}$. The mobile phase consisted of acetonitrile and distilled water ( $90 \%: 10 \%$, volume/volume) at a flow rate of $1.0 \mathrm{~mL} /$ minute. Sample injection volumes were $10 \mu \mathrm{L}$, and CsA detection was performed using a ultraviolet (UV) detector (Agilent Technologies) at a wavelength of $210 \mathrm{~nm}$. The concentration of CsA in liposomal samples to be used for the in vivo study and Restasis ${ }^{\circledR}$ emulsion was the same, and $50 \mu \mathrm{L}$ of each contained $25 \mu \mathrm{g}$ of CsA.

\section{In vitro permeation studies in Franz diffusion cells}

The permeation studies were performed using Franz diffusion cells (transdermal diffusion cell drive console with tilt; Logan Instruments Corp., Franklin Township, NJ, USA) with an orifice size of $5 \mathrm{~mm}$ and area of $0.20 \mathrm{~cm}^{2}$ as described by Aksungur et al. ${ }^{12}$ Dialysis tubing cellulose membrane (D9777100 FT; Sigma-Aldrich Co.) with a molecular weight cut-off of 14,000 Da was used. Membranes were soaked in Milli-Q water for 24 hours before mounting in Franz diffusion cells. The simulated lacrimal fluid (SLF) was prepared using $8.3 \mathrm{~g}$ of $\mathrm{NaCl}, 0.084 \mathrm{~g}$ of $\mathrm{CaCl}_{2} \cdot 2 \mathrm{H}_{2} \mathrm{O}$, and $1.4 \mathrm{~g}$ of $\mathrm{KCl}$ in $1 \mathrm{~L}$ of Milli-Q water; $10 \mathrm{~mL}$ of SLF was placed in each of six receiver compartments of the Franz diffusion cell and temperature was maintained at $32^{\circ} \mathrm{C}$, which is based on the temperature of the eye surface. The stirring rate $(300 \mathrm{rpm})$ was constant throughout the study. The total content of CsA in Restasis ${ }^{\circledR}$ and CsA-encapsulated liposomes were assayed using HPLC before applying to the donor compartment. A volume of $2 \mathrm{~mL}$ of each sample was gently placed into the donor compartment. At specified time intervals, $1 \mathrm{~mL}$ samples were withdrawn from the receiver compartment for HPLC determination and replaced immediately with an equal volume of fresh SLF solution.

\section{In vivo study of CsA liposomes in DES-induced rabbit model}

\section{Animal handling}

Male New Zealand albino rabbits aged 9 weeks, weighing 1.5-2.0 kg (Somatco Inc., Seoul, Republic of Korea) were used in this study. All experimental procedures for animal studies were approved by the Committee for the Care and Use of Laboratory Animals, Yonsei University and performed in accordance with the Committee's Guidelines and Regulations for Animal Care. All rabbits were individually housed in separate cages under standardized temperature $\left(19^{\circ} \mathrm{C} \pm 1^{\circ} \mathrm{C}\right)$, humidity $(50 \%-60 \%)$, and light (12-hour light-dark cycle) conditions. They were fed the standard diet (Somatco Inc.) and tap water.

\section{Induction of DES and the STT}

Fifteen male albino rabbits were divided into control and four different DES-induced groups, each group consisting of three rabbits. Only $0.9 \%$ (volume/volume) $\mathrm{NaCl}$ was applied to both eyes of rabbits of the control group. To induce dry eye, 1\% atropine sulfate (AS; Sigma-Aldrich Co.) was instilled into both eyes of rabbits of the four DES-induced groups three times a day for 10 days. Further, dry-eye-induced groups were divided into untreated, Restasis ${ }^{\circledR}$-treated, SCF-EPCSliposomes-treated (EPCS-treated), and SCF-S100-liposomestreated (S100-treated) groups.

The STT without anesthesia (type I) was performed to measure the aqueous portion of tear secretion in response to both conjunctival stimulation and basal non-reflex secretion. ${ }^{25,26}$ For the first 3 days, only $50 \mu \mathrm{L}$ of $1 \%$ AS was instilled into both eyes of all 12 rabbits to induce DES. From the fourth day onwards, 0.5 hours after instillation of $1 \% \mathrm{AS}, 50 \mu \mathrm{L}$ of Restasis ${ }^{\circledR}$, SCF-EPCS liposomes, and SCF-S100 liposomes were also administered into both eyes of Restasis ${ }^{\circledR}$-treated, EPCS-treated, and S100-treated groups, respectively. The Schirmer test was performed at the beginning of this experiment and on day 3, 5, 7, and 10. The test was performed using ColorBar ${ }^{\mathrm{TM}}$ STTs (Eagle Vision, 
Memphis, TN, USA), which were made of $5 \times 35 \mathrm{~mm}$ standardized filter paper strips with a blue color bar that moves with a tear front. The strip was placed inside the margin of the inferolateral third of the lower eyelid for two minutes and the level of strip wetting was measured after a few minutes. The height of the Schirmer test strips wetted by the tears was measured in millimeters and plotted versus time.

\section{CsA determination in rabbit tears}

The concentration of CsA in rabbit eyes was determined by the modified method of Aksungur et al. ${ }^{12}$ A total of 12 male New Zealand white rabbits separated into groups 1,2, and 3 were used for this study. Group 1 was treated with a Resta$\operatorname{sis}^{\circledR}$ emulsion, whereas groups 2 and 3 were treated with SCF-S100 liposomes and SCF-EPCS liposomes, respectively. A single instillation of $100 \mu \mathrm{L}$ of drug was used on the left eye, and the untreated contralateral eye was used as the control into which $0.9 \%$ (weight/volume) $\mathrm{NaCl}$ solution was administered. Tear fluid samples were collected with Schirmer filter papers, which were weighed before use and gently inserted into the inferolateral cul-de-sac of the eye, close to the middle of the eye, for 30 seconds. Immediately after collection; papers were removed, placed into the Eppendorf tubes, and weighed again. Papers were then placed in $300 \mu \mathrm{L}$ of methanol, vortexed for 3 minutes, and centrifuged (1730R; LaboGene, Seoul, Republic of Korea) at 14,000 rpm for 15 minutes. After that, CsA content in each sample was determined by HPLC assay.

\section{Ocular irritation tests}

Ocular irritation tests were used to evaluate the ocular tolerance of liposomal formulations. These tests were performed using the Draize eye and winking tests. For the Draize eye test, eight male albino rabbits were used. For acute irritation, three rabbits received three consecutive instillations of $50 \mu \mathrm{L}$ of SCF-S100 liposomes into the lower conjunctival sac with 10-minute intervals, and 30 minutes after the treatment, rabbits were examined for signs of ocular irritation. For long-term irritation, three rabbits received instillations three times a day for 7 days, and the rabbits were examined at the end of the treatment. Untreated rabbits were used as a control. The animals' discomfort and symptoms and signs in the conjunctiva, cornea, and lids were macroscopically examined using the Acute Eye Irritation/Corrosion scoring system established by the 2012 Organization for Economic Cooperation and Development for ocular irritation testing (Table 1). ${ }^{27-30}$

The ocular irritation test was also evaluated by the rabbit winking method described by Li et al. ${ }^{31}$ In this method, eight male albino rabbits were divided into two groups: Restasis ${ }^{\circledR}$ treated and liposome-treated groups. For all rabbits, $50 \mu \mathrm{L}$ of normal saline was instilled into the right eyes, whereas $50 \mu \mathrm{L}$ of Restasis ${ }^{\circledR}$ in Restasis ${ }^{\circledR}$-treated group and SCF-S100 liposomes in SCF-S100-liposomes-treated group were instilled gently into the left eyes. After instillation, drugs were spread uniformly on the eye surface. Ten seconds after the administration of the drop to the eyes, the frequency of the winking of the rabbits, for 2 minutes, was recorded. The winking of the right eye was used as a control to compare the irritation effect.

\section{Statistical analysis}

Statistical analysis was performed using SPSS software, version 18.0 for Windows (IBM Corporation, Armonk, NY, USA). Independent sample Student's $t$-tests (assuming unequal variance) were used to compare the mean values between the two formulations, whereas the one-way analysis of variance (ANOVA) test followed by Tukey's honest significant difference test and Student-Newman-Keuls tests were performed to demonstrate the statistical differences among groups. The level of significance was set as a $P$-value of less than 0.05 .

\section{Results and discussion Preparation and characterization of SCF-mediated liposomes}

Synthesized SCF-S100 and SCF-EPCS liposomes contained phosphatidylcholine (Lipoid S100 or EPCS), cholesterol, CsA, and anhydrous lactose. The initial size of SCF-S100 and SCF-EPCS liposomes was $1138 \pm 132 \mathrm{~nm}$ and $1012 \pm 170 \mathrm{~nm}$, respectively. The liposomes were homogenized at 30,000 psi

Table I Grading of ocular irritation test

\begin{tabular}{|c|c|c|c|c|c|}
\hline Grade & Discomfort & Cornea & Conjunctiva & Discharge & Lids \\
\hline 0 & No reaction & No alterations & No alterations & No discharge & No swelling \\
\hline 1 & Blinking & Mild opacity & $\begin{array}{l}\text { Mild hyperemia; } \\
\text { mild edema }\end{array}$ & $\begin{array}{l}\text { Mild discharge without } \\
\text { moistened hair }\end{array}$ & Mild swelling \\
\hline 2 & $\begin{array}{l}\text { Enhanced blinking; } \\
\text { intense tearing; } \\
\text { vocalizations }\end{array}$ & Intense opacity & $\begin{array}{l}\text { Intense hyperemia; } \\
\text { intense edema; } \\
\text { hemorrhage }\end{array}$ & $\begin{array}{l}\text { Intense discharge with } \\
\text { moistened hair }\end{array}$ & Obvious swelling \\
\hline
\end{tabular}


to produce a size of $146 \pm 28 \mathrm{~nm}$ and $148 \pm 24 \mathrm{~nm}$, respectively. The PDI of homogenized SCF-S100 and SCF-EPCS liposomes was $0.14 \pm 0.06$ and $0.13 \pm 0.05$, respectively, whereas the size and PDI of Restasis ${ }^{\circledR}$ used in this experiment were $317.6 \pm 9.3 \mathrm{~nm}$ and $0.32 \pm 0.02$, respectively. The small PDIs of SCF-mediated liposomes suggested a more homogeneous vesicle population compared with conventional CsA emulsion, Restasis ${ }^{\circledR}$. We obtained nanosized liposomes after the high-pressurized homogenization of initial SCF-S100 and SCF-EPCS liposomes, which were used for ocular delivery of CsA in this study.

The application of liposomes in ophthalmic drug delivery is immense; ${ }^{20,32}$ however, none of the liposomal drugs have been approved for ocular administration. ${ }^{33,34}$ Despite liposomes' demonstrated improvements in precorneal retention, sustained drug release, and transcorneal permeation, they still face challenges in their limited long-term physical stability and drug-loading capacity due to the inherent complex nature of their structures. ${ }^{35,36}$ Other major reasons are limited clinical and scientific results obtained with ophthalmic liposomes and difficulty in the large-scale synthesis procedure. ${ }^{23}$ All the major marketed liposomal drugs require high-grade synthetic saturated phospholipids and complex manufacturing procedures for their synthesis. Consequently, the production cost of large-scale production of liposomal drugs turns out to be very high compared with conventional drugs.

Proposed liposomal formulations in this study need a simple experimental setup with low capital cost, and naturally derived phospholipids that are much cheaper than synthetic phospholipids. Although we are using lowcost phospholipids (Lipoid S100 and Lipoid EPCS), the physicochemical properties of liposomes are not compromised. ${ }^{24}$ From the current study, we report a large-scale production of liposomal products of CsA that are cost-effective and easy to manufacture. These novel CsA formulations were nanosize-based preparations for the enhanced ocular delivery potential of CsA.

\section{SEM images of SCF-mediated liposomes}

The SEM photographs of lactose powder and SCF-S100 liposomes are shown in Figure 1. The spherical vesicular structure of SCF-S100 liposomes (Figure 1A and Figure 1B) could be easily identified compared with lactose powder (Figure 1C), which was identical to a previous transmission electron microscopy
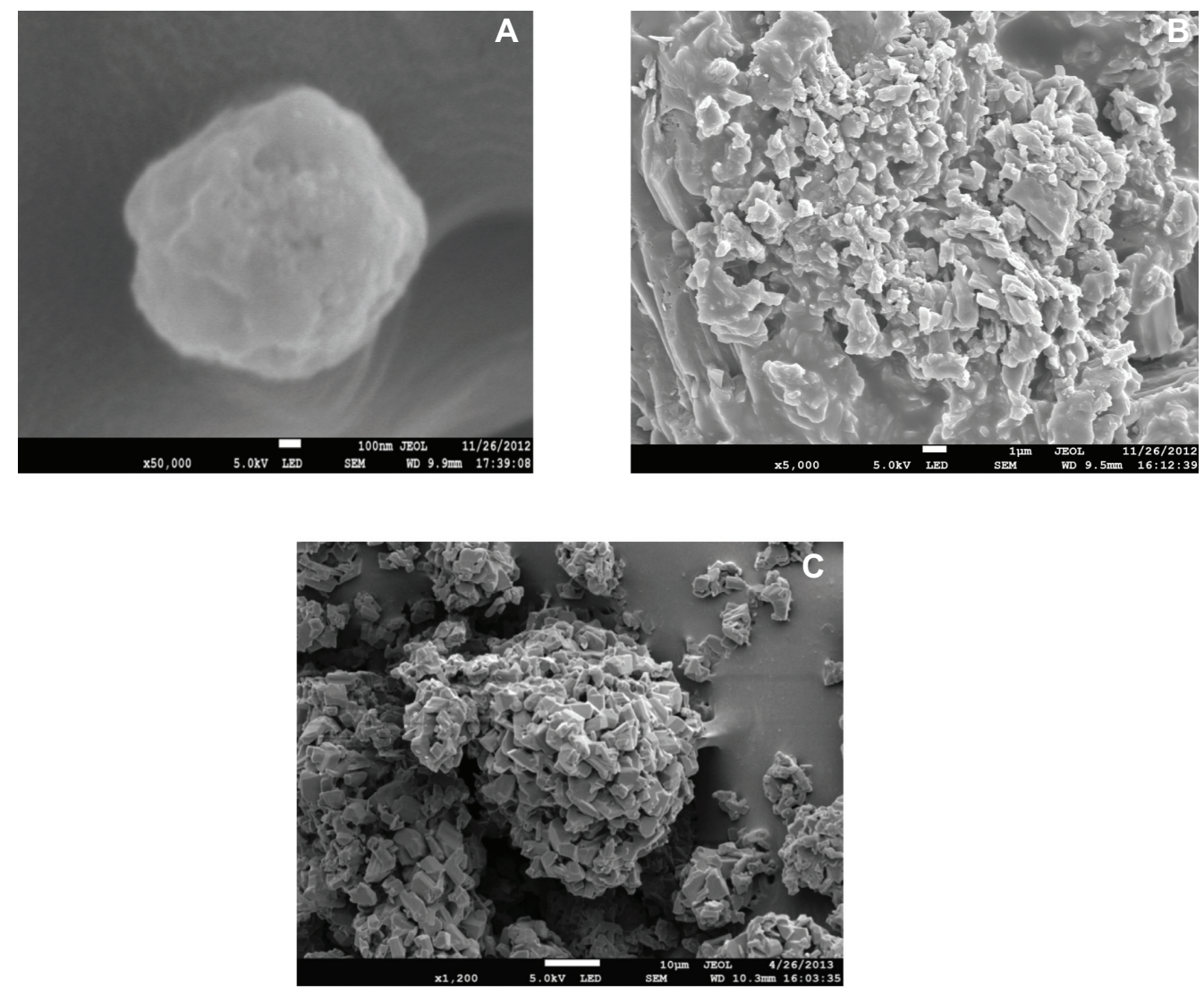

Figure I Scanning electron microscopy images of (A) SCF-SI00 liposomes, (B) SCF-SI00 liposomes, and (C) anhydrous lactose powder. Abbreviations: SCF-SI00, supercritical fluid-mediated liposomes prepared using Lipoid SIO0. 
report of CsA-liposomes. ${ }^{5}$ The particle size of SCF-S100 liposomes was about 100-200 nm, which was in good correlation with results obtained by particle size measurement.

\section{In vitro permeation studies}

The results of the in vitro permeation test are shown in Figure 2. The purpose of this study was to obtain pre-information about in vivo studies by using artificial cellulose membrane simulating human cornea.

The cumulative percentage of CsA diffused in the receptor compartment was 33.76 with Restasis ${ }^{\circledR}$ and 31.32 with SCF-S100 liposomes after 24 hours. No significant difference between the developed liposomal formulation and marketed Restasis $^{\circledR}$ in release and diffusion through the membrane, was observed.

\section{STT}

The STT values of the control group did not show any noticeable and significant changes of the tear volume production during the 10 days of in vivo experimentation. The STT value of the control group was $15.50 \pm 3.69 \mathrm{~mm}$ before starting the

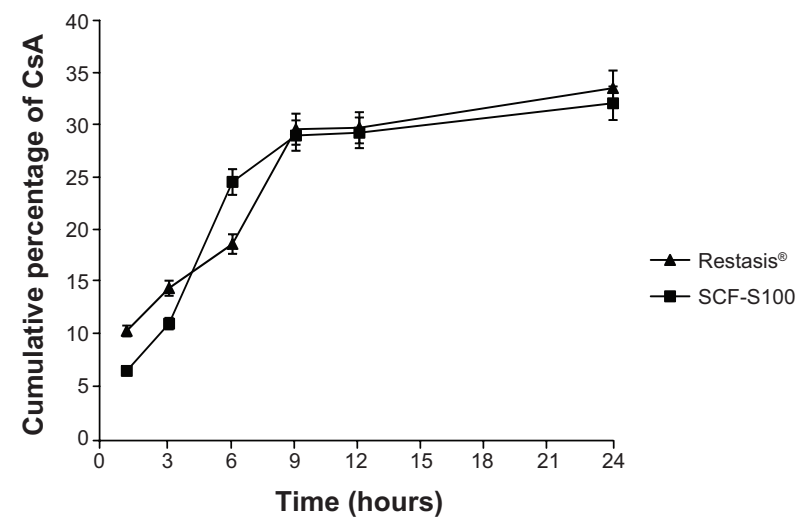

Figure 2 CsA concentration in the receiver compartment in Franz diffusion cells $(n=3)$. Note: Restasis ${ }^{\circledR}$, Allergan Inc., Irvine, CA, USA.

Abbreviations: CsA, cyclosporin A; SCF-SI00, supercritical fluid-mediated liposomes prepared using Lipoid SI00.

experiment (day 0$)$, and $15.75 \pm 3.93 \mathrm{~mm}(P=0.907)$ at the end of the experiment.

Table 2 summarizes STT values of all four dry-eyeinduced groups. On day 0 , the STT values of all groups were significantly similar (ANOVA, $P=0.498$ ) and values were around $15 \mathrm{~mm}$, which is considered a normal value.

Table 2 Schirmer tear test results in rabbits $(\mathrm{mm})$

\begin{tabular}{|c|c|c|c|c|}
\hline Days & Untreated & Restasis $^{\circledR}$-treated & EPCS-treated' & SI00-treated ${ }^{2}$ \\
\hline 0 & $13.08 \pm 1.56$ & $15.08 \pm 4.16$ & $14.50 \pm 0.70$ & $14.33 \pm 0.68$ \\
\hline$P_{1}$ & & 0.31 & 0.082 & 0.116 \\
\hline$P_{2}$ & & & 0.748 & 0.68 \\
\hline$P_{3}$ & & & & 0.686 \\
\hline$P_{4}^{3}$ & & & & 0.498 \\
\hline $3^{4}$ & $9.75 \pm 2.31$ & $8.46 \pm 3.77$ & $9.50 \pm 2.36$ & $8.66 \pm 2.40$ \\
\hline$P_{1}$ & & 0.064 & 0.468 & 0.348 \\
\hline$P_{2}$ & & & 0.163 & 0.45 \\
\hline$P_{3}$ & & & & 0.714 \\
\hline$P_{4}$ & & & & 0.823 \\
\hline 5 & $9.0 \pm 2.16$ & $11.25 \pm 1.21$ & $13.16 \pm 2.38$ & $13.83 \pm 2.25$ \\
\hline$P_{1}$ & & $0.025 *$ & $0.015^{*}$ & $0.006 *$ \\
\hline$P_{2}$ & & & 0.119 & $0.039 *$ \\
\hline$P_{3}$ & & & & 0.628 \\
\hline$P_{4}$ & & & & $0.002 *$ \\
\hline 8 & $8.75 \pm 0.97$ & $12.00 \pm 3.40$ & $14.08 \pm 3.82$ & $|4.50 \pm 3.6|$ \\
\hline$P_{1}$ & & 0.071 & $0.017^{*}$ & $0.009 *$ \\
\hline$P_{2}$ & & & 0.342 & 0.246 \\
\hline$P_{3}$ & & & & 0.85 \\
\hline$P_{4}$ & & & & $0.020 *$ \\
\hline 10 & $8.10 \pm 2.13$ & $\mathrm{II} .75 \pm 1.54$ & $|4.58 \pm 1.1|$ & $|4.9| \pm 2.20$ \\
\hline$P_{1}$ & & $0.007^{*}$ & $0.000 *$ & $0.000 *$ \\
\hline$P_{2}$ & & & $0.005^{*}$ & $0.018 *$ \\
\hline$P_{3}^{2}$ & & & & 0.749 \\
\hline$P_{4}^{3}$ & & & & $0.000 *$ \\
\hline
\end{tabular}

Notes: Each group consists of three rabbits with a total number of six eyes. Data are expressed as mean \pm standard deviation. * Significant difference when $P<0.05$. 'SCF-EPCS liposomes. ${ }^{2}$ SCF-SI 00 liposomes. $P_{1}$ : Restasis ${ }^{\oplus}$-treated, EPCS-treated, and SI00-treated groups are compared with the untreated group. $P_{2}:$ EPCS-treated and SI00-treated groups are compared with the Restasis ${ }^{\circledast}$-treated group. $P_{3}$ : SI00-treated group is compared with the EPCS-treated group. $P_{4}$ : one-way ANOVA between the four groups. Restasis ${ }^{\circledR}$, Allergan Inc., Irvine, CA, USA.

Abbreviations: ANOVA, analysis of variance; SCF-SI00, supercritical fluid-mediated liposomes prepared using Lipoid SI00; SCF, supercritical fluid; SI 00, phosphatidylcholine from soybean lecithin; EPCS, phosphatidylcholine from egg lecithin; SCF-EPCS, supercritical fluid-mediated liposomes prepared using Lipoid EPCS. 
A significant decrease in the tear production values was observed after the 3 days of $1 \%$ AS administration. Following treatment with drugs of only 2 days, a noticeable change appeared, and STT values were significantly increased for all treated groups. Interestingly, the STT values of groups treated with the liposomal formulation reached almost normal values even after 2 days of drug treatment. Compared with the conventional emulsion (Restasis ${ }^{\circledR}$ ), the liposomal formulations showed an improvement as demonstrated by the difference of the STT values between day 5 and day 0 (3.83 for Restasis ${ }^{\circledR}, P=0.090$; 1.33 for SCF-EPCS liposomes, $P=0.267$; and 0.50 for $\mathrm{S} 100$ liposomes, $P=0.646$ ). After treatment for 7 days (on day 10), there was a significant improvement $(P=0.007)$ in the STT values of the Restasis ${ }^{\circledR}$. treated group compared with the untreated group. However, the extent of the improvement observed was much higher in the SCF-EPCS $(P=0.0001)$ and SCF-S100 $(P=0.0001)$ liposome-treated groups, which were almost equal to the initial values of the respective groups. To compare two groups, independent sample Student's $t$-tests were performed and the values $\left(P_{1}, P_{2}, P_{3}\right)$ are listed in Table 2 . For the statistical differences among the four groups, one-way ANOVA ( $P=0.0001)$ showed that there were significant differences among the formulations after the treatment and the therapeutic effectiveness of the formulations (based on the STT values) was ranked by the Student-Newman-Keuls test. The order was as follows: untreated $($ rank 1$)<$ Restasis $^{\circledR}$-treated (rank 2) < SCF-EPCS-liposomes-treated (rank 3) < SCFS100-liposomes-treated (rank 4).

The therapeutic efficacy of liposomal CsA in producing more tears is supported by the STT report that revealed both liposomal formulations (especially SCF-S100) could be an alternative to Restasis ${ }^{\circledR}$ for the treatment of DES. The enhanced effect of liposomal formulations might be due to liposomal stabilization of the lipid layer of the tear film, which regulates and improves the process of moisturizing the eye and lid surface. ${ }^{37}$ The lipid layer in the eyes of rabbits and humans is of vastly different composition, and it is known that phospholipids might be a major constituent of the tear film lipid layer in rabbits but can destabilize the tear film lipid layer in humans. ${ }^{38}$ Thus, the effect of ophthalmic lipid supplements cannot be readily transferred from rabbits to humans. However, the other aspects of tear dynamics are similar and thus the data on CsA release on the ocular surface and the tolerability of the liposomal formulations can be expected to be relevant to the human eye. Developed liposomal formulations were much smaller and more homogeneous than Restasis ${ }^{\circledR}$. The smaller liposomes with homogeneous-size distribution are reported to produce uniform properties of drug release, higher density of liposome packing allowed at an ocular tissue surface, and greater optical clarity in ophthalmic applications. ${ }^{39}$

\section{Determination of the amount of CsA in rabbit tears}

The concentration of CsA in rabbit tears after administering SCF-EPCS and SCF-S100 liposomal solutions and Restasis $^{\circledR}$ to both eyes of rabbits is shown in Figure 3. The initial concentration of the drug in tear film was very high for all formulations because drainage and elimination processes started right after the drug was administered. The concentration of liposomal drugs observed at 10 minutes was significantly higher than that of the conventional emulsion, Restasis ${ }^{\circledR}$. The concentrations of all formulations were lower after 30 minutes. The fast decrease of CsA concentration could be explained by the mechanical elimination of the excess of instilled volume from the cul-de-sac. Interestingly, the concentration of liposomal formulations in the tear film was higher at each time point compared to Restasis $^{\circledR}$. After 24 hours of treatment, the concentrations of CsA were found to be $285 \pm 80 \mathrm{ng} / \mathrm{mL}, 461 \pm 97 \mathrm{ng} / \mathrm{mL}$, and $448 \pm 106 \mathrm{ng} / \mathrm{mL}$ for Restasis ${ }^{\circledR}$, SCF-S100, and SCF-EPCS liposomes, respectively.

Many studies have proved that liposomes can improve corneal uptake $\mathrm{e}^{40,41}$ and the cornea may act as a reservoir to release CsA. ${ }^{42}$ For ocular application, it is difficult to maintain therapeutic effects of drugs for a prolonged period of time because the liquid dosage forms have a tendency to be removed easily from the surface of the eye. The cornea may act as a reservoir in this case, and CsA is being

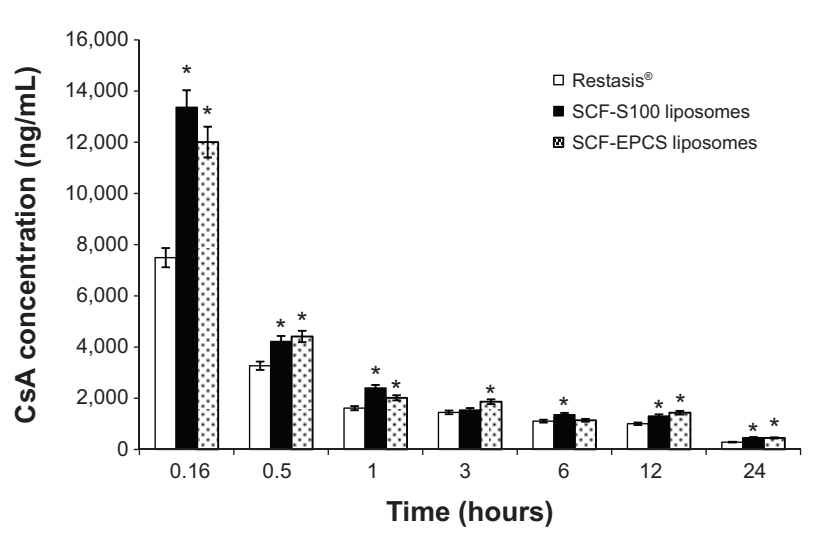

Figure 3 CsA concentration of tear film in rabbits $(n=4)$.

Note: *Significant at $P<0.05$ versus Restasis ${ }^{\circledR}$ (Allergan Inc., Irvine, CA, USA).

Abbreviations: CsA, cyclosporin A; SCF-EPCS, supercritical fluid-mediated liposomes prepared using Lipoid EPCS; SCF-SI00, supercritical fluid-mediated liposomes prepared using Lipoid S100. 
Table 3 Pharmacokinetic parameters for tears after the application of SCF-mediated CsA encapsulated liposomes and Restasis ${ }^{\circledR}(n=4)$

\begin{tabular}{lll}
\hline Formulation & ${ }^{\mathrm{a}} \mathrm{AUC}_{0-24 \mathrm{~h}}(\mu \mathrm{g} \cdot \mathbf{h} / \mathbf{m g})$ & ${ }^{\mathrm{b}} \mathbf{C}_{\max }(\mu \mathrm{g} / \mathrm{mg})$ \\
\hline Restasis $^{\circledR}$ & $24.59 \pm 8.69$ & 1.08 \\
SCF-SI00 & $32.75 \pm 9.21^{*}$ & 2.73 \\
SCF-EPCS & $32.60 \pm 11.27^{*}$ & 1.78 \\
\hline
\end{tabular}

Notes: aArea under the concentration-time curve between 0 and 24 hours. Seven time points were used for collection of the tears for the AUC calculation. 'Peak drug concentration ( $\mu \mathrm{g} \mathrm{CsA} / \mathrm{mg}$ tear). *Significant at $P<0.05$ versus Restasis ${ }^{\circledast}$ (Allergan Inc., Irvine, CA, USA).

Abbreviations: $A \cup C$, area under the concentration-time curve; $A \cup C_{0-24} \mathrm{~h}$, area under the concentration-time curve between 0 and 24 hours; $C_{\text {max }}$, peak drug concentration; CsA, cyclosporin A; SCF-EPCS, supercritical fluid-mediated liposomes prepared using Lipoid EPCS; SCF-SI00, supercritical fluid-mediated liposomes prepared using Lipoid SI00; h, hour.

released in a controlled manner. The reason for a high CsA level immediately after the instillation might be due to a burst release. Also, it could be expected that CsA would be precipitated within the limited volume of lachrymal fluid present in the precorneal environment, because of burst release, and accumulate in the cul-de-sac. ${ }^{42}$

The pharmacokinetic parameters were calculated in order to examine the elimination of CsA from the precorneal area as shown in Table 3. Restasis ${ }^{\circledR}$ and liposomal formulations have significantly different $\mathrm{AUC}_{0-24 \mathrm{~h}}$, indicating that the nature of the formulation affects the AUC. The highest $\mathrm{AUC}_{0-24 \mathrm{~h}}$ obtained with SCF-S100 was 32.75 $\pm 9.21 \mu \mathrm{g} \cdot \mathrm{h} / \mathrm{mg}$, but both liposomes had statistically similar $\mathrm{AUC}_{0-24 \mathrm{~h}}$, whereas Resta$\operatorname{sis}^{\circledR}$ had a significantly lower value of $24.59 \pm 8.69 \mu \mathrm{g} \cdot \mathrm{h} / \mathrm{mg}$ $(P=0.001)$. The data is in accordance with the CsA determination in rabbit tear film and other in vitro permeation studies. The pharmacokinetic study showed that liposomal formulations have significantly higher tear film concentration of CsA as well as $\mathrm{AUC}_{0-24 \mathrm{~h}}$ compared to the marketed emulsion, Restasis ${ }^{\circledR}$. The release of the drug through liposomes was supposed to be prolonged, and it was observed that after 24 hours of the instillations, liposomal drugs were more predominantly present than Restasis ${ }^{\mathbb{B}}$ in the tear film. This result suggests that the liposomal formulations might be therapeutically more effective after the ocular administration for the treatment of DES in rabbits.

\section{Ocular irritation tests}

The Draize eye test is a governmentally endorsed method to evaluate the safety of materials meant for use in or around the eyes, by instilling ophthalmic agents onto the cornea and conjunctiva of laboratory animals. ${ }^{29}$ The Draize eye test results showed that there was no sign of discomfort appearing after the instillation of the novel SCF-S100 liposomal formulation. Grade zero was reported for all of the parameters examined. For the long-term irritation test, animals were

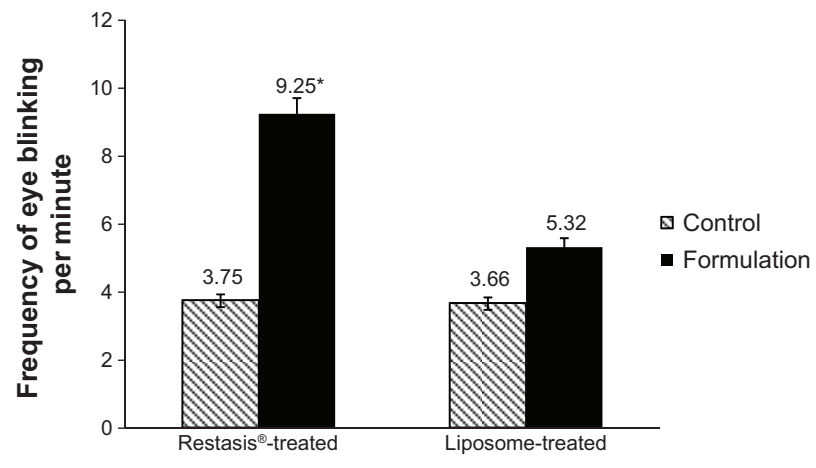

Figure 4 Frequency of eye blinking after instillation of $50 \mu \mathrm{L}$ samples in rabbit eyes $(n=4)$.

Notes: Right eyes were used as controls and normal saline was administered to the control eyes. Left eyes were used for treatment in which formulations of Restasis ${ }^{\circledR}$ (Allergan Inc., Irvine, CA, USA) and SCF-SI00 liposomes were administered. *Significant at $P<0.05$ versus control.

Abbreviation: SCF-SI00, supercritical fluid-mediated liposomes prepared using Lipoid S100.

sacrificed after the experiment and the signs of changes in the conjunctiva, cornea, and lids were macroscopically examined, and there was no difference observed between the treated and untreated groups. In conclusion, there were no signs of alteration observed after the treatment with the novel liposomal formulation.

The report of blinking in the rabbits is shown in Figure 4. There were no significant differences in the blinking of the control eyes and liposome-treated eyes $(P=0.088)$. On the other hand, the Restasis ${ }^{\circledR}$-treated group showed a significant increase in blinking after treatment with Restasis ${ }^{\circledR}$. In the Restasis ${ }^{\circledR}$-treated group, the total number of blinks observed during 2 minutes was $7.50 \pm 0.71$; in control eyes, that improved significantly to $18.50 \pm 0.71$ blinks $(P=0.002)$. The blink count of the liposome-treated eyes was significantly lower compared with the Restasis ${ }^{\circledR}$-treated group, and it was least in the control eyes of both groups. Ocular irritation of Restasis ${ }^{\circledR}$ has already been reported by many groups. ${ }^{11,43}$ Restasis $^{\circledR}$ is an oil-in-water emulsion which contains castor oil that causes irritation to the eyes.

CsA at $0.05 \%$ (Restasis $^{\circledR}$ ) is known to be one of the standard options for the treatment of moderate to severe DES, but because of its prominent side effects (ocular irritation) it is not patient-friendly. ${ }^{23}$ The use of corticosteroids is the other possible option. However, long-term use of corticosteroids is also limited because of numerous side effects, including ocular hypertension, cataract, and corneal thinning. ${ }^{44}$ Very interestingly, the proposed liposomal formulation showed significantly lower eye irritation compared with that of Restasis $^{\circledR}$. A similar result was also supported by Khan et a ${ }^{43}$ where a CsA nanosphere formulation had a significantly lower irritation effect than Restasis ${ }^{\circledR}$. The current study showed that there was no sign of changes in the conjunctiva, cornea, 
and eye lids after the acute and long-term tests. For causing less irritation of eyes, liposomal formulations are supposed to be very simple in compositions that contain naturally derived phosphatidylcholine, which is highly compatible with biological membranes, ${ }^{45}$ and liposomal formulations have a smaller size compared to Restasis ${ }^{\circledR}$.

\section{Conclusion}

To the best of our knowledge, none of the previous studies in humans or animal models have focused on the effectiveness of liposomal CsA for the treatment of DES. In the present study, the newly synthesized SCF-mediated liposomes showed significant effects such as improved tear production in dry eyes, higher tear film concentration, and less ocular irritation in the treatment of DES in rabbits. Our results strongly support that the use of liposomal formulations provide a better efficacy compared to that of Restasis ${ }^{\circledR}$; thus current formulations hold promise as an alternative therapy for DES. More specifically, SCF-mediated SCF-S100 liposomes might be an ideal candidate for further development; the cost effectiveness of the preparation was reasonable for large-scale production compared to the existing liposomal drugs. However, further investigations (eg, detailed clinical efficacy, toxicity, and other in vivo studies) will need to be carried out in humans to confirm the advantages of the newly developed liposomal formulations over the conventional product, Restasis ${ }^{\circledR}$.

\section{Acknowledgments}

This research was financially supported by a grant from the Korean Health Technology R\&D Project, Ministry of Health, Welfare and Family Affairs, Republic of Korea (A092018). The work was also supported in part by the Yonsei University Global Specialization Project of 2013. The authors would like to acknowledge Mr Benjamin Joon Lee, who assisted in the proofreading of the manuscript.

\section{Disclosure}

The authors report no conflicts of interest in this work. The authors alone are responsible for the content and writing of this paper.

\section{References}

1. Javadi MA, Feizi S. Dry eye syndrome. J Ophthalmic Vis Res. 2011; 6(3):192-198.

2. Lee SY, Han SJ, Nam SM, et al. Analysis of tear cytokines and clinical correlations in Sjögren syndrome dry eye patients and non-Sjögren syndrome dry eye patients. Am J Ophthalmol. 2013;156(2):247-253.e1.

3. Stonecipher KG, Chia J, Onyenwenyi A, Villanueva L, Hollander DA. Health claims database study of cyclosporine ophthalmic emulsion treatment patterns in dry eye patients. Ther Clin Risk Manag. 2013;9:409-415.
4. Baiza-Durán L, Medrano-Palafox J, Hernández-Quintela E, LozanoAlcazar J, Alaníz-de la O JF. A comparative clinical trial of the efficacy of two different aqueous solutions of cyclosporine for the treatment of moderate-to-severe dry eye syndrome. Br J Ophthalmol. 2010;94(10): 1312-1315.

5. Karn PR, Cho W, Park HJ, Park JS, Hwang SJ. Characterization and stability studies of a novel liposomal cyclosporin A prepared using the supercritical fluid method: comparison with the modified conventional Bangham method. Int J Nanomedicine. 2013;8:365-377.

6. Rodriguez-Aller M, Kaufmann B, Guillarme D, et al. In vivo characterisation of a novel water-soluble cyclosporin A prodrug for the treatment of dry eye disease. Eur J Pharm Biopharm. 2012;80(3): $544-552$.

7. Di Tommaso C, Valamanesh F, Miller F, et al. A novel cyclosporin A aqueous formulation for dry eye treatment: in vitro and in vivo evaluation. Invest Ophthalmol Vis Sci. 2012;53(4):2292-2299.

8. Donnenfeld E, Pflugfelder SC. Topical ophthalmic cyclosporin: pharmacology and clinical uses. Surv Ophthalmol. 2009;54(3):321-338.

9. Pflugfelder SC. Antiinflammatory therapy for dry eye. Am J Ophthalmol. 2004;137(2):337-342.

10. Wilson SE, Perry HD. Long-term resolution of chronic dry eye symptoms and signs after topical cyclosporine treatment. Ophthalmology. 2007;114(1):76-79.

11. Roberts CW, Carniglia PE, Brazzo BG. Comparison of topical cyclosporin, punctal occlusion, and a combination for the treatment of dry eye. Cornea. 2007;26(7):805-809.

12. Aksungur P, Demirbilek M, Denkbaş EB, Vandervoort J, Ludwig A, Ünlü N. Development and characterization of cyclosporin A loaded nanoparticles for ocular drug delivery: cellular toxicity, uptake, and kinetic studies. J Control Release. 2011;151(3):286-294.

13. Gupta C, Chauhan A. Ophthalmic delivery of cyclosporin A by punctal plugs. J Control Release. 2011;150(1):70-76.

14. Al-Angary A, Bayomi M, Khidr S, Al-Meshal M, Al-Dardiri M. Characterization, stability and in vivo targeting of liposomal formulations containing cyclosporin. Int J Pharm. 1995;114(2):221-225.

15. Al-Meshal MA, Khidr SH, Bayomi MA, Al-Angary AA. Oral administration of liposomes containing cyclosporin: a pharmacokinetic study. Int J Pharm. 1998;168(2):163-168.

16. Guan P, Lu Y, Qi J, et al. Enhanced oral bioavailability of cyclosporin A by liposomes containing a bile salt. Int $J$ Nanomedicine. 2011;6: 965-974.

17. Alghadyan AA, Peyman GA, Khoobehi B, Liu KR. Liposome-bound cyclosporine: retinal toxicity after intravitreal injection. Int Ophthalmol. 1988;12(2):105-107.

18. Alghadyan AA, Peyman GA, Khoobehi B, Milner S, Liu KR. Liposomebound cyclosporine: clearance after intravitreal injection. Int Ophthalmol. 1988;12(2):109-112.

19. Milani JK, Pleyer U, Dukes A, et al. Prolongation of corneal allograft survival with liposome-encapsulated cyclosporine in the rat eye. Ophthalmology. 1993;100(6):890-896.

20. Mishra GP, Bagui M, Tamboli V, Mitra AK. Recent applications of liposomes in ophthalmic drug delivery. J Drug Deliv. 2011;2011: 863734.

21. Ebrahim S, Peyman GA, Lee PJ. Applications of liposomes in ophthalmology. Surv Ophthalmol. 2005;50(2):167-182.

22. Lallemand F, Felt-Baeyens O, Besseghir K, Behar-Cohen F, Gurny R. Cyclosporin A delivery to the eye: a pharmaceutical challenge. Eur $J$ Pharm Biopharm. 2003;56(3):307-318.

23. Yavuz B, Bozdağ Pehlivan S, Ünlü N. An overview on dry eye treatment: approaches for cyclosporin A delivery. Scientific World Journal. 2012;2012:194848.

24. Hwang SJ, Karn PR, Cho W, Kang H, Sun BK, inventors; Foundation of University-Industry Research Collaboration of Yonsei University, assignee. Ophthalmic liposome composition for treating dry eye syndrome comprising cyclosporin. Korean patent application 10-20140006954. 2014 Feb 20.

25. Shafaa MW, El Shazly LH, El Shazly AH, El gohary AA, El hossary GG. Efficacy of topically applied liposome-bound tetracycline in the treatment of dry eye model. Vet Ophthalmol. 2011;14(1):18-25. 
26. Gin J, Wong VG, inventors; Visionex, assignee. Schirmer tear test. United States patent 5006310. 1991 Apr 9.

27. Diebold Y, Jarrín M, Sáez V, et al. Ocular drug delivery by liposome-chitosan nanoparticle complexes (LCS-NP). Biomaterials. 2007;28(8):1553-1564.

28. Organization for Economic Co-operation and Development. OECD Test Guideline 405: Acute Eye Irritation/Corrosion. Paris: Organization for Economic Co-operation and Development; 2012. http://ntp.niehs.nih. gov/iccvam/SuppDocs/FedDocs/OECD/OECD-TG405-2012-508.pdf. Accessed March 23, 2013.

29. Wilhelmus KR. The Draize eye test. Surv Ophthalmol. 2001;45(6): 493-515.

30. Li N, Zhuang C, Wang M, Sun X, Nie S, Pan W. Liposome coated with low molecular weight chitosan and its potential use in ocular drug delivery. Int J Pharm. 2009;379(1):131-138.

31. Li X, Nie SF, Kong J, Li N, Ju CY, Pan WS. A controlled-release ocular delivery system for ibuprofen based on nanostructured lipid carriers. Int J Pharm. 2008;363(1-2):177-182.

32. Meisner D, Mezei M. Liposome ocular delivery systems. Adv Drug Deliv Rev. 1995;16(1):75-93.

33. Karn PR, Cho W, Hwang SJ. Liposomal drug products and recent advances in the synthesis of supercritical fluid-mediated liposomes. Nanomedicine (Lond). 2013;8(9):1529-1548.

34. Allen TM, Cullis PR. Liposomal drug delivery systems: from concept to clinical applications. Adv Drug Deliv Rev. 2013;65(1):36-48.

35. Liu S, Jones L, Gu FX. Nanomaterials for ocular drug delivery. Macromol Biosci. 2012;12(5):608-620.

36. Law SL, Huang KJ, Chiang $\mathrm{CH}$. Acyclovir-containing liposomes for potential ocular delivery. Corneal penetration and absorption. J Control Release. 2000;63(1-2):135-140.
37. Craig JP, Purslow C, Murphy PJ, Wolffsohn JS. Effect of a liposomal spray on the pre-ocular tear film. Cont Lens Anterior Eye. 2010;33(2): 83-87.

38. Butovich IA, Lu H, McMahon A, Eule JC. Toward an animal model of the human tear film: biochemical comparison of the mouse, canine, rabbit, and human meibomian lipidomes. Invest Ophthalmol Vis Sci. 2012;53(11):6881-6896.

39. Guo LSS, Redmann CT, Radhakrishnan R, inventors; Liposome Technology, Inc., assignee. Ophthalmic liposomes. US Patent 4804539. $1989 \mathrm{Feb} 14$

40. Lee VH, Takemoto KA, Iimoto DS. Precorneal factors influencing the ocular distribution of topically applied liposomal inulin. Curr Eye Res. 1984;3(4):585-591.

41. Dai Y, Zhou R, Liu L, Lu Y, Qi J, Wu W. Liposomes containing bile salts as novel ocular delivery systems for tacrolimus (FK506): in vitro characterization and improved corneal permeation. Int J Nanomedicine. 2013;8:1921-1933

42. Kachi S, Hirano K, Takesue Y, Miura M. Unusual corneal deposit after the topical use of cyclosporin as eyedrops. Am J Ophthalmol. 2000; 130(5):667-669.

43. Khan W, Aldouby YH, Avramoff A, Domb AJ. Cyclosporin nanosphere formulation for ophthalmic administration. Int J Pharm. 2012; 437(1-2):275-276

44. Okanobo A, Chauhan SK, Dastjerdi MH, Kodati S, Dana R. Efficacy of topical blockade of interleukin-1 in experimental dry eye disease. Am J Ophthalmol. 2012;154(1):63-71.

45. Huang $\mathrm{CH}$. Phosphatidylcholine vesicles. Formation and physical characteristics. Biochemistry. 1969;8(1):344-352.
International Journal of Nanomedicine

\section{Publish your work in this journal}

The International Journal of Nanomedicine is an international, peerreviewed journal focusing on the application of nanotechnology in diagnostics, therapeutics, and drug delivery systems throughout the biomedical field. This journal is indexed on PubMed Central, MedLine, CAS, SciSearch $\AA$, Current Contents $\AA /$ Clinical Medicine,

\section{Dovepress}

Journal Citation Reports/Science Edition, EMBase, Scopus and the Elsevier Bibliographic databases. The manuscript management system is completely online and includes a very quick and fair peer-review system, which is all easy to use. Visit http://www.dovepress.com/ testimonials.php to read real quotes from published authors. 